\title{
Design and Analysis of Cylindrical Dielectric $₫$ Resonator Antenna for 5G Application
}

\author{
Loya Surendra, Habibulla Khan
}

\begin{abstract}
DRA's are used for $5 G$ communications of large bandwidth at sub $6 \mathrm{GHz}$ and millimeter to Terahertz. The channel capacity can achieve a very high data rate i.e. $C=B \log 2(1+S N R)$ where $C$ is the channel capacity and $B$ is the bandwidth of the channel. The cylindrical resonator antenna operating in hybrid $H_{E M} M_{11 s}$ mode. In this paper a cylindrical dielectric resonator antenna(CDRA) with frequency range $(2-6 \mathrm{GHz})$.The cylindrical dielectric resonator with radius $r=10 \mathrm{~mm}$ and height $h=10 \mathrm{~mm}$. the CDRA material is alumina ceramic with a permittivity of $\varepsilon_{D R A}$ is 9.9 and the resonant frequency is $f_{\mathrm{r}}=4 \mathrm{GHz}$. The substrate will be is Rogers $R T 5880$ with $\varepsilon_{r}=2.2$ and $\tan \mathcal{S}=0.0009$, the thickness is $1.52 \mathrm{~mm}$. The CDRA is excited about the microstrip line. so the cdra is coupled electromagnetically by this microstrip line and below the substrate, we have a ground plane with annealed alumina so we have no radiation or low below the substrate all the radiation is top of the CDRA. The proposed antenna is simulated using CST microwave studio software and the designed antenna will operate for $5 G$ applications and we can consider massive MIMO antenna array configurations. This design analyses the parameters of CDRA.
\end{abstract}

Keywords-CDRA, MASSIVE MIMO, 5G, DRA, Microstrip line

\section{INTRODUCTION}

The growth of wireless communication technologies demands advancements in antenna technology. The essential need for efficient and low-profile antennas are required for $5 \mathrm{G}$ technologies. The development of antenna structures with performances considerably enhanced over traditional antenna structures and methodologies. The development of the dielectric resonator antenna technologies has taken significant strides in overcoming fundamental limitations in the design of broadband and efficient antenna structures. The antenna structures like the microstrip patch suffer from reduced efficiency due to the stratified nature of the design resulting in surface wave loss together with the presence of a conducting patch contributing to conductor loss in the antenna structure. The dielectric resonator antenna is suited for low-loss applications due to the absence of conductors or surface wave loss. It is observed that the frequency range of interest for many systems had gradually progressed upward to the millimeter and near millimeter range. At these frequencies the conductor loss of metallic antennas becomes severe and the efficiency of the antenna.

Revised Manuscript Received on December 15, 2020.

*Corresponding author

Loya Surendra*, Research scholar, Konerulakshmaiah education foundation, Vaddeswaram and associate professor, usha Rama College of Engineering and Technology , AP, India. Email: surendra.loya2007@gmail.com

Habibulla khan, Professor and Dean Student Affairs, Konerulakshmaiah Education Foundation, Vaddeswaram, AP, India. Email: habibulla@kluniversity.in

(c) The Authors. Published by Blue Eyes Intelligence Engineering and Sciences Publication (BEIESP). This is an open access article under the CC BY-NC-ND license (http://creativecommons.org/licenses/by-nc-nd/4.0/)

\section{ANTENNA DESIGN}

There are different kinds of 3d structures are available for DRA. The DRA makes use of the radiating mode of the dielectric resonator. The resonant frequency is determined by its dimension and dielectric constant. The CDRA is a short form of cylindrical dielectric resonator antenna that can be excited by using microstrip, aperture, probe so different excitation types would generate different modes inside these resonators and will have different resonant frequencies. The cylindrical dielectric resonator antenna using alumina ceramic with permittivity of 9.9 and the dimensions of cdra is in the order of its radius $\mathrm{r}=10 \mathrm{~mm}$ and height $\mathrm{h}=10 \mathrm{~mm}$, the microstrip feed is used with a resonant frequencyof cdra is 4GHz.

Table I: Design parameters of a CDRA

\begin{tabular}{|l|l|l|l|}
\hline Parameter & Value(mm) & Parameter & Value(mm) \\
\hline $\mathrm{x}$ & 60 & $\mathrm{R}$ (radius) & 10 \\
\hline $\mathrm{y}$ & 60 & H(height) & 10 \\
\hline $\mathrm{L}$ & 40 & T(thickness) & 4.65 \\
\hline
\end{tabular}

A. Advantages of DRA

$>$ The size of DRA depends on the resonant frequency and dielectric constant of the materials $\left(\lambda_{0} / \Gamma \epsilon_{\mathrm{r}}\right)$.

$>$ DRA will give high radiation efficiency and a high degree of freedom and versatility, it uses several feeding mechanisms

\section{B. Disadvantages of DRA}

DRA has a high fabrication cost due to high permittivity material.

$>$ It is difficult to design a modified shape due to material rigidity, difficult to get specific dielectric.

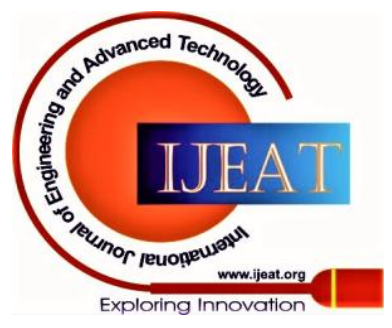




\section{Design and Analysis of Cylindrical Dielectric Resonator Antenna for 5G Application}

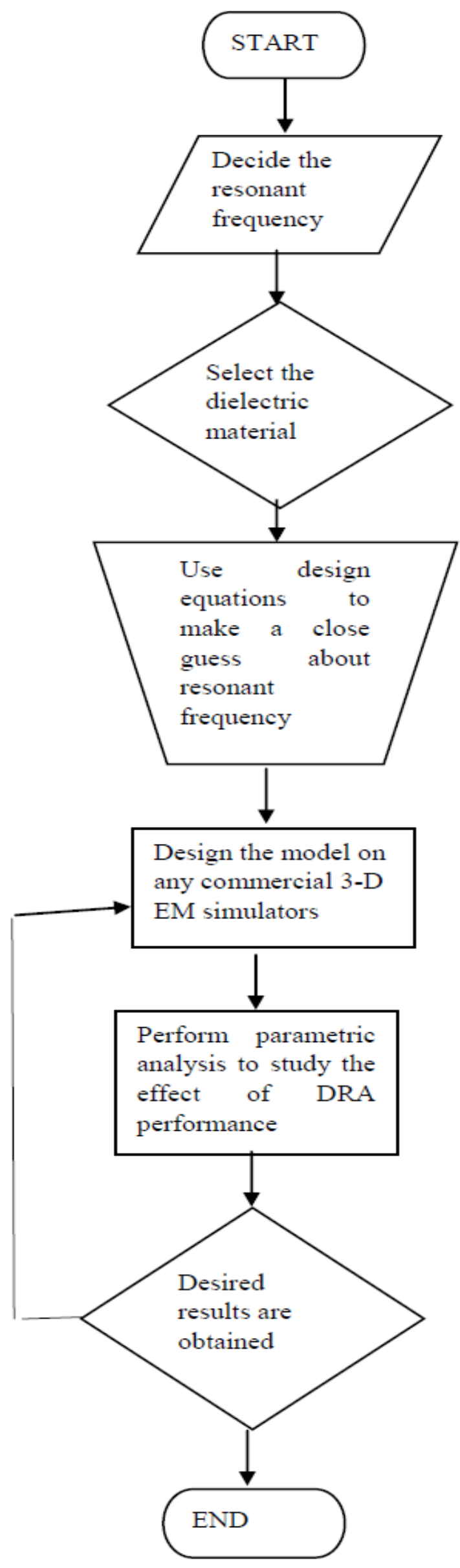

The formula to calculate the resonant frequency of a CDRA is

$$
f_{r=\frac{c}{2 \pi r \sqrt{ } \epsilon_{D R A}}}\left[1.71 t \frac{r}{h}+0.1578\left(\frac{r^{2}}{h}\right)\right]
$$

The above expression is only valid for hybrid mode and the same dielectric resonator antenna can be excited by using different modes i.e TE and TM modes then the resonant frequency expressions are different for these modes.

\section{DESIGN OF CDRA IN CST}

By using CST Studio designed cdra initially considered substrate Rogers RT5880(lossy), then placed on that substrate CDR with alumina ceramic in a cylindrical shape and created ground plane with copper annealed and this CDRA is excited with microstrip line.

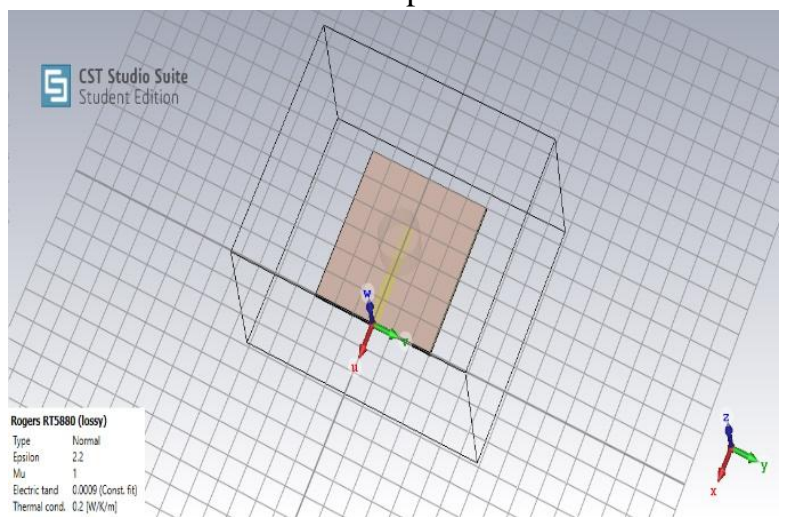

Fig 2:Substrate Rogers RT5880(lossy) in CST

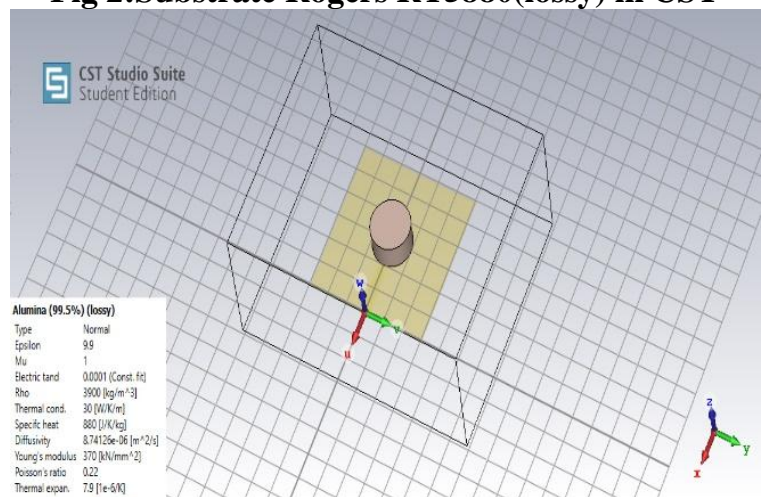

Fig 3: DRA in Cylindrical shape in CST

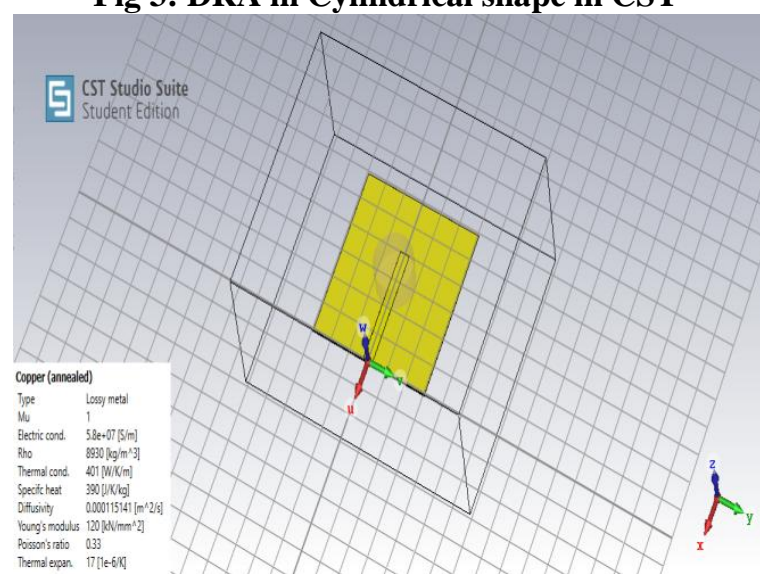

Fig 4: Ground plane created below the substrate

Fig: 1 Flowchart of CDRA

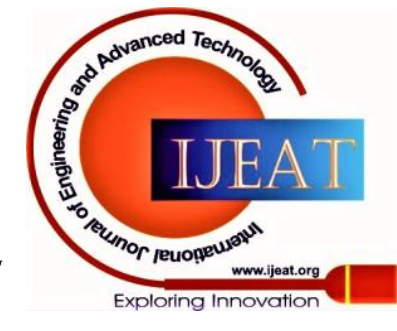




\section{RESULTS AND DISCUSSION}

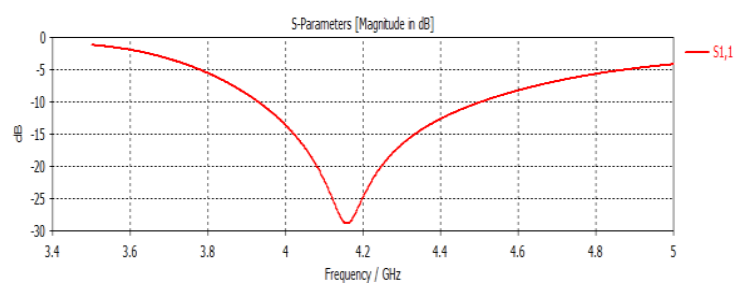

Fig 5:S parameter vs frequency

The CDRA is resonating at $4.16 \mathrm{GHz}$ and as per calculation it needs to resonate at $4 \mathrm{GHz}$ but nearly the same.

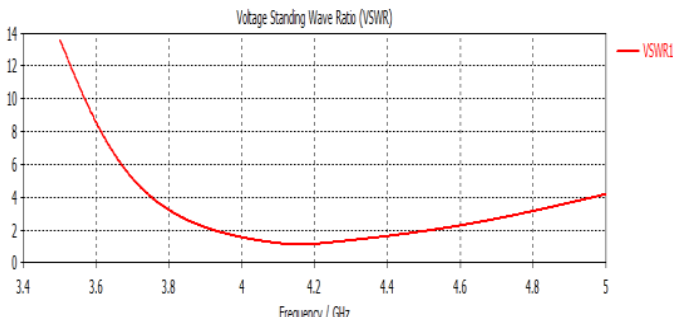

Fig 6:Vswr vs Frequency

The VSWR of the proposed antenna from the figure we can observe that the VSWR of the proposed antenna in the sub $6 \mathrm{GHz}$ is at the resonant frequency of the antenna is 1 which shows the antenna has proper impedance matching at the resonant frequency.

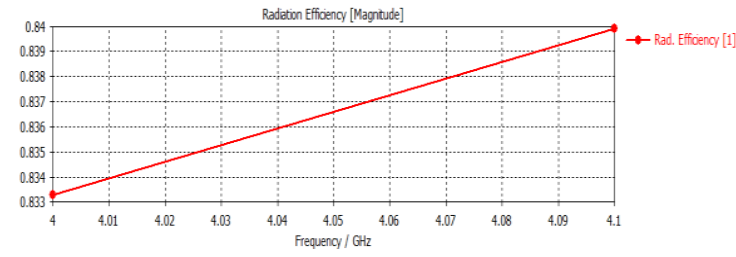

Fig 7:Radiation efficiency vs frequency

The radiation efficiency of the proposed antenna is maximum at the resonant frequency.

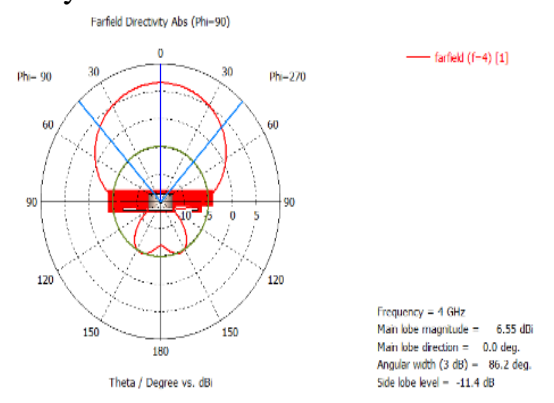

Fig 8: Far-field 1D measurement at $4 \mathrm{GHz}$

For the proposed CDRA the main lobe magnitude is $6.55 \mathrm{dBi}$ and main lobe direction 0.0deg and the angular width $(3 \mathrm{~dB})$ is $86.2 \mathrm{deg}$ and the sidelobe level is $-11.4 \mathrm{~B}$.

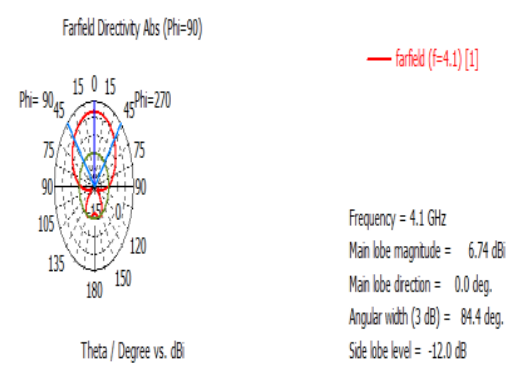

Fig 9:Far-field 1D meaurement at 4.1GHz

For the proposed CDRA the main lobe magnitude is $6.74 \mathrm{dBi}$, and main lobe direction is 0.0deg and the angular width (3dB) is 84.4deg and the sidelobe level is $-12.0 \mathrm{~dB}$.

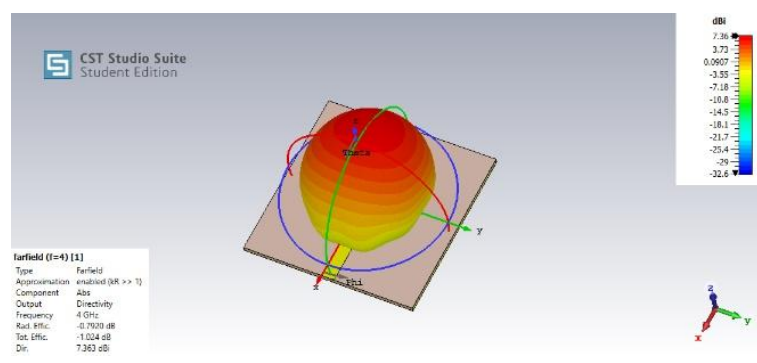

Fig 10: Far-field 3D measurement at $4 \mathrm{GHz}$

The far-field is measured at $4 \mathrm{GHz}$. The directivity of the proposed CDRA is $7.363 \mathrm{dBi}$.The radiation efficiency is $0.7920 \mathrm{~dB}$ and total efficiency is $-1.024 \mathrm{~dB}$.

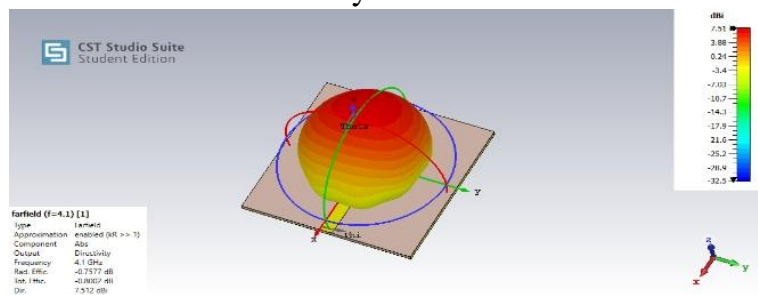

Figure 11: Far-field 3D measurement at 4.1GHz The far-field radiation is measured at frequency $4.1 \mathrm{GHz}$. The directivity of the proposed CDRA is 7.512dBiThe radiation efficiency is $-0.7577 \mathrm{~dB}$ and the total efficiency is $-0.8002 \mathrm{~dB}$.

\section{CONCLUSION}

The Cylindrical dielectric resonator antenna is designed and simulated by using CST microwave studio software in this paper. The proposed antenna is operating in the sub6GHz band. The far-field pattern and S parameters and VSWR are measured at the resonant frequency as per theoretical at $4 \mathrm{GHz}$ and $4.1 \mathrm{GHz}$. The radiation efficiency at $4 \mathrm{GHz}$ is $0.7920 \mathrm{~dB}$ and the total efficiency is $-1.024 \mathrm{~dB}$ and thedirectivity is $7.363 \mathrm{bBi}$ and at $4.1 \mathrm{GHz}$ the radiation efficiency is $-0.7577 \mathrm{~dB}$ and the total efficiency is $-0.8002 \mathrm{~dB}$ and the directivity of the CDRA is 7.512dBi.The CDRA is better than a microstrip patch antenna. So the proposed antenna can be used in 5G applications and it can be used as an antenna element in Massive Mimo antenna array configurations.

\section{ACKNOWLEDGEMENTS}

I thank my guide for his support and encouragement to complete this work.

\section{REFERENCES}

1. Petosa, A., Dielectric Resonator Antenna Handbook, 1st Edition, Artech House, Boston, 2007

2. A petosa, A. Ittipiboon, Y.M. M. Antar, D. Rossoe and M. Cuhaci, "R ecent advances in dielectric resonator antenna technology," IEEE AntennasPropagat. Mag., Vol.40 pp 35-48 June 1998.

3. Nano Dielectric resonator antennas for $5 \mathrm{G}$ applications Rajveer S.Yaduvanshi,Gaurav Varsney by CRC press 2020

4. Petosa, A., Dielectric Resonator Antenna Handbook, 1st Edition, Artech House, Boston, 2007.

5. Pan, Y.M., Leung, K.W., Luk, K.M.: 'Design of the millimeter-wave rectangular dielectric resonator antenna using a higher-order mode', IEEE Trans. Antennas Propag., 2011, 59, (8), pp. 2780-2788.
Published By:

Blue Eyes Intelligence Engineering

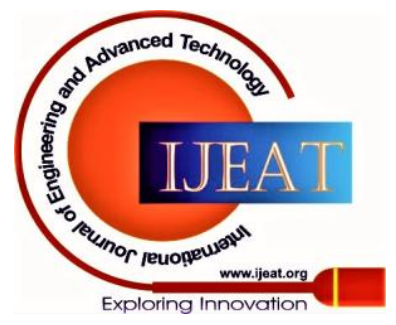

(c) Copyright: All rights reserved. 


\section{Design and Analysis of Cylindrical Dielectric Resonator Antenna for 5G Application}

6. G.Kumar, M.Singh, S.Ahlawat, R.S. Yaduvanshi, "Design of stacked Rectangular Dielectric Resonator Antenna for wideband Applications", Wireless pers.commun, Vol.109,no.3 pp.16611672,2019 .

7. Hong, W., et al., "Multibeam antenna technologies for $5 \mathrm{G}$ wireless communications," IEEE Trans. Antennas Propag., Vol. 65, No. 12, 6231-6249, Dec. 2017.

8. Niu, Y., Y. Li, D. Jin, L. Su, and A. V. Vasilakos, "A survey of millimeter wave (mmWave) communications for 5G: Opportunities and challenges," Wireless Networks, Vol. 21, No. 8, 2015.

\section{AUTHORS PROFILE}

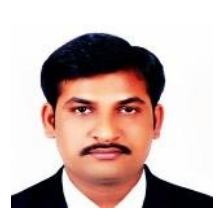

Surendra Loya received hisBTech degree in Electronics andCommunication Engineering from JNTUH, Andhra Pradesh, India in 2008, and MTech degree in Radiofrequency and Microwave engineering from Gitam University, Visakhapatnam, Andhra Pradesh in 2011. He is presently serving as an Associate professor at the Department of Electronics and Communication Engineering, Usha Rama College of Engineeringand Technology, Telaprolu, Andhra Pradesh, India. He is currently a Ph.D. student in ECE, KL college of Engineering, Koneru Lakshmiah education foundation Guntur, Greenfields, vaddeswaram, India.

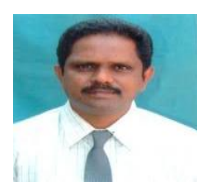

Habibulla khan received his BTech in ECE from Nagarjuna university Andhra Pradesh in the year 1984.M.E in Applied Electronics from Bharathiaruniversity,Tamilnadu in the year 1987.Ph.D from Andhra University in the area of slot antnnas in as professor and Dean(SA). the year2007.presently he is working in K L university

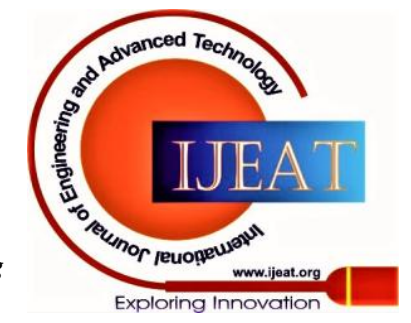

